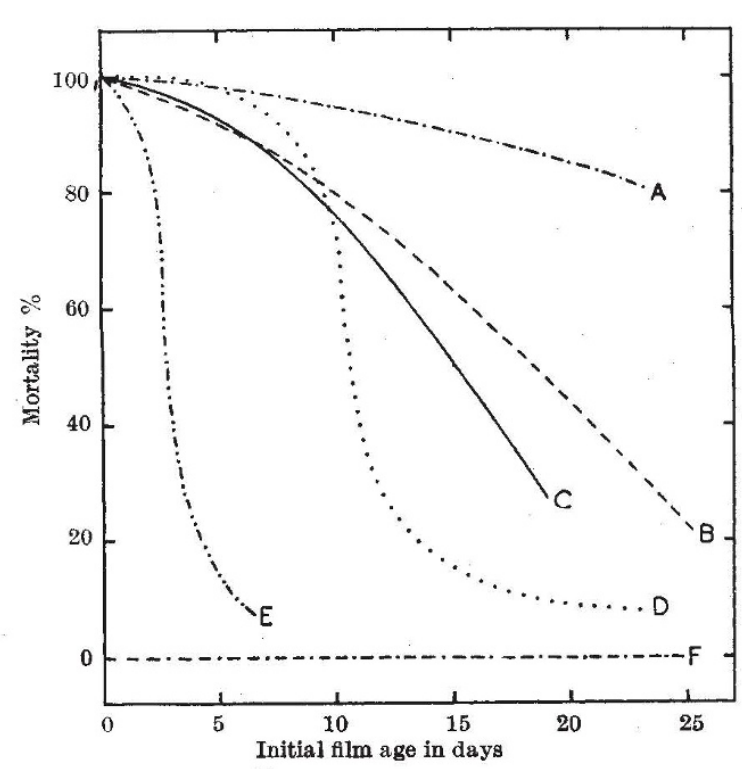

THE TOXIOITY TO $T$. castaneum OF FILMS FORMRD ON PRETREATED CEMENT BY 1.5 MGM./SQ. CM. OF 1.6 PER OENT PYRETHRINS IN P.31. INSECTS CONYINED ON FILMS FOR 6 DAYS. PRETREATAIENTS : $A$, SIZE (10 PKR CENT); $B$, GKIATIN (5 PER CENT) ; $C$, STARCH PASTE ; $D$, POLYVINYL AOETAL EMULSIO
$E$, BRICKWORK SEALING PAINT; $F$, NO PRETREATMENT.

ence in toxicity between insecticidal films on wood and on limewash.

Ways have been sought to increase the toxicity and persistence of these films. The most striking results were obtained by pretreating the surfaces, before application of the insecticide, with substances which might be expected to reduce greatly the rate of sorption into the substrate, and so to render the insecticide more available to insects walking over the surface. Many substances, including water, hygroscopic materials, sodium silicate preparations, paints, varnishes and colloidal gels were put through preliminary tests to assess their value as pretreatments. The relation between film toxicity and film age was determined for some of the most promising of these when applied to cement. The accompanying graph shows the results. Insecticidal films formed by deposits of $1.5 \mathrm{mgm}$./sq. $\mathrm{cm}$. of 1.6 per cent pyrethrins remained highly toxic under laboratory conditions for more than three weeks on some coatings.

After further investigation, size and gelatin, applied in aqueous colloidal solution, have been selected as the most useful of the materials at present available; gelatin was better than size at equal concentration. A solution of pyrethrins was used in most of the laboratory work, but coatings of size or gelatin also supported solutions of other insecticides, including D.D.T., in an oil base.

A trial of size under practical conditions indicated that it was effective, provided that a continuous coating was formed.

This work forms part of the programme of work of the Pest Infestation Laboratory, and this note is published by permission of the Department of Scientific and Industrial Research.

Pest Infestation Laboratory, P. S. Hewlett. E. A. Parkin. Slough, Bucks. April 9.

${ }^{1}$ Potter, Ann. Appl. Biol., 22, 769 (1935) ; 25, 836 (1938).

\section{Preliminary Report on the Purification and the Molecular Weight of Hypertensin}

DURING an investigation on the chemistry of hypertensin some facts have emerged worth a brief report. Hypertensin has been purified to a very high degree, its effect in raising the blood pressure of a cat in chloralose anæsthesia equalling that of adrenaline. The smallest dose eliciting an appreciable effect on the blood pressure lies in the vicinity of $0.5 \gamma$. Important steps in the ultimate purification are chromatography ${ }^{1}$ and electrodialysis.

The former rests upon the fact that hypertensin is adsorbed on aluminium oxide from a methyl alcoholic solution and eluted with appropriate mixtures of methyl alcohol and water.

For the electrodialysis an apparatus constructed by Hammarsten ${ }^{2}$ was employed. Parchment paper was used as cathodic membrane, and goatskin, which is impermeable to hypertensin, as anodic membrane. It was found that if the reaction in the centre compartment was held more alkaline than $p H \quad 7.5$ with barium hydroxide, no hypertensin passed into the cathodic compartment. Thanks to this fact, inorganic salts and other impurities could be removed without loss of activity. When thereafter the reaction in the centre compartment was made acid to $p \mathrm{H} 3$ with sulphuric acid, hypertensin rapidly passed out into the cathodic compartment. $1 \mathrm{mgm}$. of this preparation obtained in good yield (70-80 per cent) had an activity corresponding to $35 \mathrm{mgm}$. tyramine phosphate. The nitrogen content (Kjeldahl) was $13 \cdot 6$ per cent.

From the last experiment together with earlier electrophoresis experiments ${ }^{3}$ it was concluded that hypertensin must be neutral or nearly neutral in character. Hence a determination of the diffusion constant at neutral reaction would give information - though approximate - on the molecular weight of hypertensin. The apparatus and technique of Theorell ${ }^{4}$ were used, and the diffusion was followed by activity measurements. To prevent inactivation of hypertensin the experiments were performed at $0^{\circ} \mathrm{C}$. In two different determinations the diffusion constant was found to be $1.20 \times 10^{-6} \mathrm{~cm} .{ }^{2} / \mathrm{sec}$. resp. $\mathrm{I} \cdot 18 \times 10^{-6} \mathrm{~cm} .^{2} / \mathrm{sec}$. Assuming for hypertensin a specific volume of $0 \cdot 75$, the diffusion constant obtained corresponds to a molecular weight of 2,750 . Pehr Edman.

Chemistry Department, Karolinska Institutet, Stockholm, and

Insulin Laboratory of AB. Vitrum, Stockholm, Sweden.

${ }^{1}$ Edman, P., Ark. Kemi, Mineral., Geol., B, 18, No. 2 (1944). a Åren, G., Diss., Skand. Arch. Physiol., 69 (1934).

s Edman, P., v. Euler, U., Jorpes, E., and Sjöstrand, T. O., J. Physiol., 101,284 (1942).

"Theorell, H., Biochem. Z., 275, 19 (1934-35).

\section{British and Continental Races of the Starling, Sturnus vulgaris L., in Canada}

AN account of the differences in timing of the reproductive cycles of the British and Continental races of the European starling has been given by Bullough', and the consequent differences in external morphology and in behaviour have been emphasized. It was suggested that these differences, particularly in behaviour, may prevent cross-breeding, and that in any event the two races must be considered as subspecifically distinct. 